\title{
Prompt Attention of the Diagnostic Medical Imaging Centers in Tehran: An Experience of People with Physical Disability
}

\author{
Manijeh Alavi ${ }^{1,2}$, Ameneh Setareh Forouzan ${ }^{1}$, Homeira Sajjadi ${ }^{3}$, Mohammad Reza Khodaie Ardakani ${ }^{1}$, \\ Mohsen Shati ${ }^{4}$ and Maziar Moradi-Lakeh ${ }^{5,{ }^{*}}$ \\ ${ }^{1}$ Social Determinants of Health Research Center, University of Social Welfare and Rehabilitation Sciences, Tehran, Iran \\ ${ }^{2}$ Deputy for Research and Technology, Ministry of Health and Medical Education, Tehran, Iran \\ ${ }^{3}$ Social Welfare Management Research Center, University of Social Welfare and Rehabilitation Sciences, Tehran, Iran \\ ${ }^{4}$ Department of Aging, University of Social Welfare and Rehabilitation Sciences, Tehran, Iran \\ ${ }^{5}$ Department of Community and Family Medicine, Preventive Medicine and Public Health Research Center, Iran University of Medical Sciences, Tehran, Iran \\ "Corresponding author: Department of Community and Family Medicine, Preventive Medicine and Public Health Research Center, Iran University of Medical Sciences, Shahid \\ Hemmat Highway, Postal Code: 1449614535, Tehran, Iran. Fax: +98-2188052248, Email: moradilakeh.m@iums.ac.ir
}

Received 2018 April 29; Revised 2018 July 05; Accepted 2018 September 30.

\begin{abstract}
Background: Nowadays, change in the pattern of diseases to chronic has been with increasing use of medical imaging services. People with physical disability require continuous diagnostic and therapeutic services.

Objectives: This study aimed to measure the waiting time for receiving medical imaging services and to examine sociodemographic factors associated with the poor experience of these people.

Patients and Methods: In a cross-sectional study to assess the responsiveness of comprehensive rehabilitation centers in Tehran in 2016 - 2017, 610 people with physical disabilities who were referred to 10 comprehensive physical rehabilitation centers for rehabilitation services were asked whether they had used medical imaging services during their rehabilitation. The 477 participants (218 women) with positive response consisted the sample of this study. A checklist was used for data collection. T test, Chi-Square and Multiple Logistic Regression Model were used for analytical reports.

Results: Poor experience in prompt attention of centers was reported by $26 \%$ of public diagnostic service users while $16 \%$ of private sector users and $21.2 \%$ by total sample. Waiting time for appointment and waiting time at the center were significantly longer in public medical imaging centers compared to the private sector $(\mathrm{P}<0.05)$. Overall experience of public service users about prompt attention was poorer than the private sector $(\mathrm{P}<0.05)$. Physical status (odd ratio $[\mathrm{OR}]=3.2 ; 95 \%$ confidence interval $[\mathrm{CI}]=1.3-7.8$ ) and duration of disability $(\mathrm{OR}=0.28 ; 95 \% \mathrm{CI}=0.09-0.9)$ were the predictors of poor experience of respondents about prompt attention in public and private centers respectively.

Conclusion: From the service users' viewpoint, private centers had better performance in prompt attention than public centers. Attention to physical condition and duration of disability in scheduling diagnostic services is recommended.
\end{abstract}

Keywords: Prompt Attention, Diagnostic Medical Imaging Centers, Physical Disability, Tehran

\section{Background}

In the recent century, the pattern of diseases is changed from acute to chronic diseases. Because of the characteristics of chronic diseases and long lasting conditions, continuous diagnostic, preventive and therapeutic services are needed (1). These comprehensive health services are mainly provided by health systems. Health system has intrinsic goals as health improvement, responsiveness and fairness of health costs $(2,3)$. These systems are also concerned about improving the access to health services and health system effectiveness (4). Access refers to ability of a person or population group to receive health services they need from the health system that means the availability of these services and awareness of people about the existing services and ability to receive the service in a reasonable time (5). Diagnostic medical imaging services are of high importance and are used widely in chronic conditions and diseases (1). Most health conditions are not concisely diagnosed without using medical imaging (6). Therefore, receiving diagnostic medical imaging services in a reasonable time in order to follow up the process of diagnosis and treatment and prevention of further consequences is very important (5). Request for medical diagnostic imaging has been increased during recent 
years that may lead to longer waiting times. Access to medical imaging centers and having a pleasant waiting experience are believed to have a positive impact on the client as a part of the health providing process (1). Assessment of waiting time is very important in improving the quality of care in medical imaging in which high standards are expected (6). It has been reported that patients spend considerable time to receive medical imaging (7). Evidence from Italy suggests that public centers usually provide imaging services in a long waiting period and this is the reason for choosing private suppliers (1). Advanced access scheduling aims to decrease wait times for physician visits emphasizing access to same-day appointments. Increasing waiting time has been reported as a factor for the decreasing level of client satisfaction (8).

Disability as a chronic condition needs continuous diagnostic, therapeutic and rehabilitation services (9). People with disabilities compose approximately one billion or $15 \%$ of total population in the world $(9,10)$. Although this percentage varies in different countries, it is increasing. Physical disabilities account for more than half of all disabilities, and $70 \%$ of people with physical disabilities are living in developing countries (11). It is estimated by some researchers that more than 11 million people are suffering from disability in Iran $(9,11)$. Furthermore, higher rates of accidents, especially traffic accidents and population aging are of the most important reasons for the increasing number of people with disabilities, especially physical disability (9). Despite higher needs of health services for people with disabilities compared to people without disabilities, people with disabilities face problems regarding access to diagnostic and long term care services (5). An investigation in Canada showed that while the population of people with disability increases, unmet health care needs is increasing and people with disability are two to three times more likely to have unmet needs than people without disability (12). People with disabilities face more difficulties in access to health services (13). Prompt attention as a domain of health system responsiveness refers to how people have access to the services and how long it takes to receive care $(14,15)$.

Beside rehabilitation, medical imaging as a para clinical care is one of the services that people with disabilities are usually referred to use. For people with physical disability, prompt attention (e.g., waiting times) in diagnostic medical centers is even more important as disability is a chronic condition needing continuous attention (13). Furthermore, lack of adequate information needs recording of the experiences of people with disabilities in health indicators and health care services (16). There are studies about waiting time for receiving radiology services $(1,7,17)$, but the special needs of people with physical disabilities who are one of the main diagnostic service users has not been highlighted. In our pilot study that was performed in summer 2016 in one of the comprehensive rehabilitation centers of Tehran regarding health system responsiveness to people with physical disabilities, medical imaging, as a part of the health care process, was considerably noticed by the respondents in terms of time scheduling of the medical imaging centers.

\section{Objectives}

The main purpose of this paper was to present the experiences of people with physical disability about prompt attention in terms of timely schedule of medical imaging centers, and to assess their socio-demographic factors that predict their poor experience.

\section{Patients and Methods}

This paper provides analysis of the experience of people with disabilities who used medical imaging services during their rehabilitation process.

In a cross-sectional study to assess the responsiveness of comprehensive physical rehabilitation centers in Tehran in 2016 - 2017, through Quota sampling, the number of 610 people over 18 years of age with physical disability who were referred to 10 comprehensive physical rehabilitation centers (five private and five public) to use rehabilitation services were the primary sample. Geographic location of the centers was so that we could have a good coverage of clients from several regions as North, South, West, East and center of Tehran.

These people were asked if they had used medical imaging services during their rehabilitation process. The 477 participants with positive response composed the sample of this study. A checklist was used including questions about the type of center and imaging services they used, and waiting time to visit the center, waiting time at the center to receive the service and waiting time to receive the imaging result, and finally, their overall experience regarding the prompt attention of medical imaging centers. The overall experience of people about prompt attention of medical imaging centers was asked by a question on a five-point Likert from very good to very bad. Experiences were considered as good if the responses were very good and good and as poor in case of any others (moderate, bad, 
very bad). A socioeconomic checklist was used to gather socio-demographic information. Questionnaires of activities of daily living(ADL) and instrumental activities of daily living (IADL) were also used to assess physical functioning of the participants. Data were gathered through face to face interview by the principal investigator as well as two trained interviewers.

\subsection{Terms and Variables}

In this study, physical disability was considered as musculoskeletal impairments that could be congenital or caused by accidents or diseases, or other sources as specified by the respondent.

Prompt attention was considered as the amount of waiting time for health service (18). In this study, waiting times consisted of:

1- Waiting time for an appointment: The waiting time for a person from the time of the request until the time set for the visit to the center (based on days)

2- Waiting time at the center: Waiting time from check in to center till receiving medical imaging service (based on hours)

3- Waiting time for receiving the report of diagnostic imaging (based on days).

Outcome variable was the experience of people about prompt attention (a dichotomous variable as good or poor).

Independent variables were selected based on search in texts of WHO and articles in international websites such as ISI web of science and PubMed and Scopus and Iranian website as Magiran with no time limitation about users' satisfaction and health system responsiveness (18-26) and then three experts in the field of radiology assessed the variables and a list was provided including sex (man or woman according to self-recognition), age (self-report as $\geq$ 60 and $<60$ categories), education (self-report and categorized in three groups as $<5,5-12$ and $12<$ years) (15), perceived socio-economic class as low, middle, high (15), occupation (self-report and categorized in three groups proposed by the Statistical Center of Iran as non-occupied, occupied without wage, occupied with wage), economic situation was considered as residential area per capita [ratio of residential area to household size as quantile from the lowest (Q1) to highest (Q5)], duration of disability (selfreport as years), health situation on a 5-scale Likert from very good to very bad [self-report, as good health (good and very good responses) and as bad health (any other responses)], physical status as daily physical functioning (considered as scores from activities of daily living [ADL] questionnaire) and daily instrumental functioning (considered as scores from instrumental activities of daily living [IADL] questionnaire). There were three possible responds for each activity in both questionnaires: dependent, need help and independent which were scored as 0 , 1 and 2 respectively. The total score for ADL and IADL for each respondent was then calculated. In ADL total scores of 0 - 7 were considered as completely dependent, 8 - 11 was interpreted as partial dependent, and 12 - 16 showed independence. For IADL: Scores 0 - 6, 7 - 10, and 11 - 14 showed completely dependent, partially dependent, and independent, respectively, having a health insurance (self-report as yes or no) and satisfaction with the health insurance (selfreport as yes or no).

In this study, the type of medical imaging center as public or private was considered based on the participants' self-report and was also checked with the list provided by medical universities in Tehran.

\subsection{Data Analysis}

Descriptive statistics including frequency, percentage, mean and standard deviation (SD) are presented. In analytical statistics, T test was done for comparison of means and for relationship of categorical variables Chi-Square was done. For predicting the individual factors for poor experience of respondents, multiple logistic regression model (forward) was implemented. For this purpose, first we performed bivariate analysis (binary regression) to assess the association of each independent variable with the outcome variable. The significant level of 0.2 or less was considered for bivariate analysis (27). Statistical significance was defined as $\leq 0.05$ for other analytical statistics including full multiple regression model. Predictors are shown as adjusted odds ratio (adjusted OR) and 95\% confidence interval (CI). Statistical analysis was done by SPSS version 16 software.

The current study was approved by the ethical committee of the University of Social Welfare and Rehabilitation Sciences (ethical code: IR.USWR.REC.1395.86). Management board of private and public centers as well as medical universities in the area permitted this study to be conducted. We explained the goals of the study to all the individuals who had the inclusion criteria and assured them that the information would remain confidential. Then in case of satisfaction to participate in the study, informed consent was obtained. 


\section{Results}

Of all respondents, the number of 231 (48.8\%) used private imaging centers and 242 (51.2\%) used public ones. All the 477 respondents (100\%) were referred to one imaging center in Tehran to receive their service and did not use several centers. The most services used by the people who were referred to medical imaging centers were 251 (52.84\%) for MRI, 201 (42.31\%) for X-ray radiology, 19 (4\%) for CT-scan and four $(0.85 \%)$ for sonography. There were 218 women (46.3\%), while the number of men was 252 (53.7\%) in all centers. Mean age was $46(\mathrm{SD}=14.9)$ in all the respondents, while $44.4(\mathrm{SD}=14.2)$ and $47.6(\mathrm{SD}=15.5)$ were users of public and private imaging centers, respectively. Respondents' mean years of education was $13(\mathrm{SD}=5.0)$ in private centers and 12.2 $(\mathrm{SD}=4.3)$ in public centers. Mean years of living with disability were $4.9(\mathrm{SD}=5.83)$ and $4.4(\mathrm{SD}=5.2)$ in users of private and public imaging centers, respectively. Median of years living with disability was 3 in all the respondents.

Socio-economic characteristic of people with disability who used medical imaging services during their rehabilitation process is shown in Table 1 by type of the center.

Waiting time for an appointment as well as waiting time for receiving the result of the diagnostic tests by center type are shown in Table 2.

There was a significant difference in waiting time to make an appointment between public and private medical imaging centers $\left[\chi^{2}(4)=11.66, P=0.02\right]$, but no difference was found in the waiting time for receiving the result of the diagnostic test $\left[\chi^{2}(3)=5.5, P=0.13\right]$.

Mean waiting time at the center from entrance till starting the process of diagnostic service was 59 and 75 minutes for private and public centers, respectively. A significant difference was found in means of private and public centers $[\mathrm{P}=0.003, \mathrm{t}=2.97,95 \%$ confidence interval $(-26.8$ to -5.4$)$ ].

No significant difference was found in waiting time for receiving the result of the diagnostic test between private and public centers. Poor performance of imaging centers from the respondents' view in total sample and by center type are illustrated Figure 1.

As shown in Figure 1, public centers in timeliness performed poorer from the respondents' view. The difference was significant $\left[\chi^{2}(1)=7.02, \mathrm{P}=0.008\right]$.

Results of bivariate analysis of association between sociodemographic characteristics and poor experience of people with physical disability about waiting time of medical imaging centers including unadjusted coefficient (crude odds ratio) are shown in Table 3.
Table 3 illustrates that in the public sector, functional abilities of people with disability in terms of daily physical and instrumental activities of daily living (IADL) were associated with poor experience of the service users in timing $(\mathrm{P} \leq 0.2)$, which were the input of full model.

Table 4 illustrates the predictor variable of poor experience of people with physical disability about timing of medical imaging centers of Tehran.

Table 4 shows that people who were dependent in their instrumental activities of daily living were 3 times more likely to be unsatisfied with the timing of public imaging centers.

It can be seen in Table 3 that variables as age, perceived social class, satisfaction with health insurance, duration of physical disability, self-report health status and economic situation (as residential area per capita) show the association with poor experience of the service users in timing of the private centers $(\mathrm{P} \leq 0.2)$ which were put in full model.

Table 5 shows the socio-demographic predictors of poor experience of people with physical disability about waiting time of the private medical imaging centers of Tehran.

As seen in Table 5, people with shorter duration of disability are $72 \%$ less likely to be unsatisfied with the timing of private imaging centers.

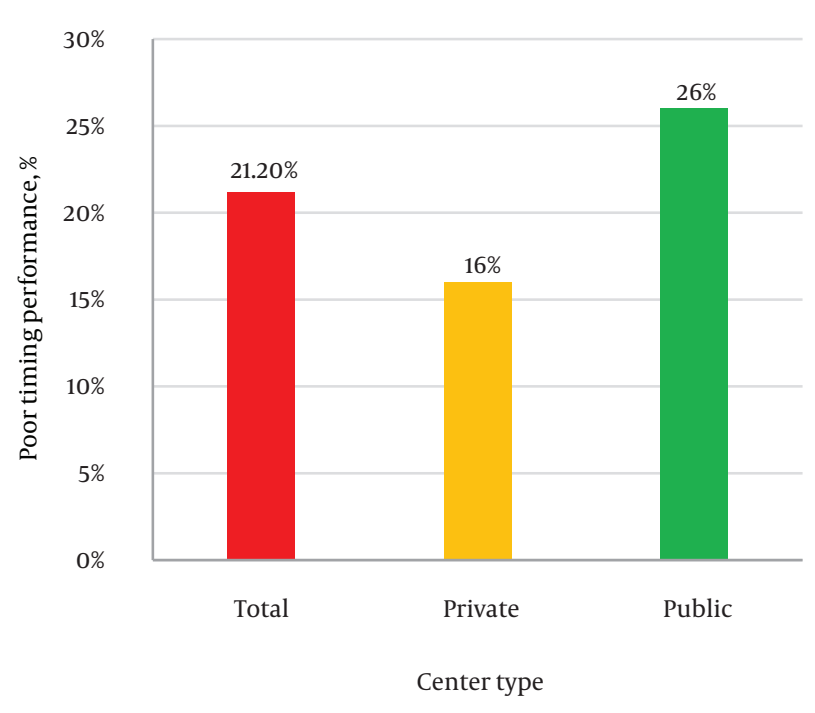

Figure 1. Poor timing performance of medical imaging centers from the respondents' view 


\begin{tabular}{|c|c|c|}
\hline Characteristic & Private medical imaging center & Public medical imaging center \\
\hline \multicolumn{3}{|l|}{ Sex } \\
\hline Male & $123(53.2)$ & $130(54.2)$ \\
\hline Female & $108(46.8)$ & $110(45.8)$ \\
\hline \multicolumn{3}{|l|}{ Age } \\
\hline $18-59$ & $173(75.2)$ & $193(49)$ \\
\hline$\geq 60$ & $57(24.8)$ & $79.8(20.2)$ \\
\hline \multicolumn{3}{|l|}{ Education } \\
\hline$<5$ (elementary) & $7(3)$ & $10(4.1)$ \\
\hline 5 - 12 (intermediate/high school) & $90(39.1)$ & $129(53.3)$ \\
\hline$>12$ (upper) & $133(57.8)$ & $103(42.6)$ \\
\hline \multicolumn{3}{|l|}{ Perceived social position } \\
\hline Low & $17(7.6)$ & $66(28)$ \\
\hline Middle & $167(74.2)$ & $167(70.8)$ \\
\hline High & $41(18.2)$ & $3(1.3)$ \\
\hline \multicolumn{3}{|l|}{ Employment } \\
\hline Unemployed & $23(10.3)$ & $26(11.1)$ \\
\hline Employed without wage & $79(35.4)$ & $88(37.4)$ \\
\hline Employed with wage & $121(54.3)$ & $121(51.5)$ \\
\hline \multicolumn{3}{|l|}{ Health status (self-report) } \\
\hline Good & $113(48.9)$ & $128(53.3)$ \\
\hline Bad & $118(51.1)$ & $112(46.7)$ \\
\hline \multicolumn{3}{|l|}{ Having health insurance } \\
\hline Yes & $214(95.1)$ & $218(91.2)$ \\
\hline No & $11(4.9)$ & $21(8.8)$ \\
\hline \multicolumn{3}{|l|}{ Satisfaction with health insurance } \\
\hline Yes & $143(66.5)$ & $124(56.9)$ \\
\hline No & $72(33.5)$ & $94(43.1)$ \\
\hline \multicolumn{3}{|l|}{ Duration of physical disability } \\
\hline Under median & $84(59.2)$ & $103(63.6)$ \\
\hline Upper median & $58(40.8)$ & $59(36.4)$ \\
\hline \multicolumn{3}{|l|}{ Daily physical functioning } \\
\hline Dependent & $15(6.6)$ & $11(4.6)$ \\
\hline Help needed & $59(26)$ & $73(30.3)$ \\
\hline Independent & $153(67.4)$ & $157(65.1)$ \\
\hline \multicolumn{3}{|l|}{ Daily instrumental functioning } \\
\hline Dependent & $39(17.2)$ & $38(15.8)$ \\
\hline Help needed & $109(48)$ & $132(54.8)$ \\
\hline Independent & $79(34.8)$ & $71(29.5)$ \\
\hline \multicolumn{3}{|l|}{ Economic situation } \\
\hline The lowest (Q1) & $46(20.09)$ & $70(28.57)$ \\
\hline Low & $34(14.85)$ & $53(21.63)$ \\
\hline Middle & $42(18.34)$ & $51(20.82)$ \\
\hline High & $52(22.71)$ & $41(16.73)$ \\
\hline The highest (Q5) & $55(24.02)$ & $30(12.24)$ \\
\hline
\end{tabular}

Abbreviations: Q, quantile.

${ }^{\mathrm{a}}$ Values are expressed as No. (\%). 


\begin{tabular}{|c|c|c|c|c|c|c|}
\hline & \multicolumn{3}{|c|}{ Waiting time for an appointment with medical imaging center } & \multicolumn{3}{|c|}{ Waiting time for receiving the report of the diagnostic test } \\
\hline & Private & Public & Total imaging centers & Private & Public & Total imaging centers \\
\hline Same day & $140(60.9)$ & $117(48.5)$ & $257(54.6)$ & $35(15.4)$ & $40(16.7)$ & $75(16.1)$ \\
\hline 1 - 2 days & $67(29.1)$ & $95(39.4)$ & $162(34.4)$ & $50(22)$ & $33(13.8)$ & $83(17.8)$ \\
\hline 3 - 5 days & $10(4.3)$ & $18(7.5)$ & $28(5.9)$ & $89(39.2)$ & $106(44.2)$ & $195(41.8)$ \\
\hline 6 - 10 days & $13(5.7)$ & $9(3.7)$ & $22(4.7)$ & $53(23.3)$ & $61(25.4)$ & $114(24.4)$ \\
\hline More than 10 days & - & $2(0.4)$ & $2(0.4)$ & - & - & $467(100)$ \\
\hline
\end{tabular}

${ }^{\mathrm{a}}$ Values are expressed as No. (\%).

\section{Discussion}

According to the investigation on responsiveness of comprehensive physical rehabilitation centers to people with physical disability, in a pilot study, we found that although medical imaging was one of the most used services during rehabilitation process, people were concerned about the prompt attention of these centers. As the majority of people using rehabilitation services had diagnostic imaging tests, this paper provides an analysis of the experience of people with disabilities who used medical imaging services during their rehabilitation process. We aimed to measure the waiting time for services, also assess the difference between waiting time in the private and public sectors and identify the socio-demographic factors that may affect the overall experience of these people in this regard.

In this assessment, the majority of time-seekers to schedule an appointment, were given a maximum of two days apart both in public and private centers, which indicates that imaging centers have met at an acceptable time. Furthermore, in general, waiting time for appointment was significantly less in private imaging centers than publics. This finding was in line with the investigation carried out in Italy by Nuti and Vainieri in which the waiting time for public medical imaging centers was more than private centers (1). One possible explanation for this difference could be that there are more references to the public sector in comparison with the private sector. Although there is no significant difference in the use of the private and public sector among the clients in our study, public centers have generally more clients and this might be one of the possible reasons.

In this study, we found that the average waiting time for taking imaging service from check in to the center till start of the diagnostic process was about one hour in the private sector, while one hour and a quarter in the public sector, that was significantly shorter in the private sector than the public. Of course, studies in other countries show that dissatisfaction rises when this time is longer than 20 minutes (17). An important recommendation to all centers could be adjusting the number of daily admissions and the interval between patients according to the type of diagnostic test to reduce waiting times, as well as considering the emergency cases that might be referred.

In this study, there was no significant difference between the private and public sectors regarding the duration of submission of the medical imaging result to clients. This suggests that after implementing the diagnostic imaging, performance in relation to timing was relatively similar.

We found that from the respondents' point of view, public centers had poorer performance in timeliness. It supports the study by Nuti and Vainieri indicating that the increase in waiting times has led to the increase of people's interest in the private sector (1).

Although more than one socio-demographic factor was associated with poor experience of people with physical disability about timeliness of medical imaging centers, the predictors were duration of disability as well as capability of instrumental activity. This indicates that by increasing of years living with disability and dependence in instrumental activities of these people, there is a need for more attention of medical imaging centers.

This study had strengths and weaknesses. To our knowledge, this was the first study on this vulnerable target group in Iran and it was implemented based on needs assessment in our pilot study. The current study was according to WHO guidelines. Furthermore, our samples were from comprehensive rehabilitation centers that as referral centers covered almost good representative people with physical disability. However, we faced limitations as well. We just studied the timeliness of medical imaging centers and the experience of people with physical disability considering the factors that predicted their poor experi- 


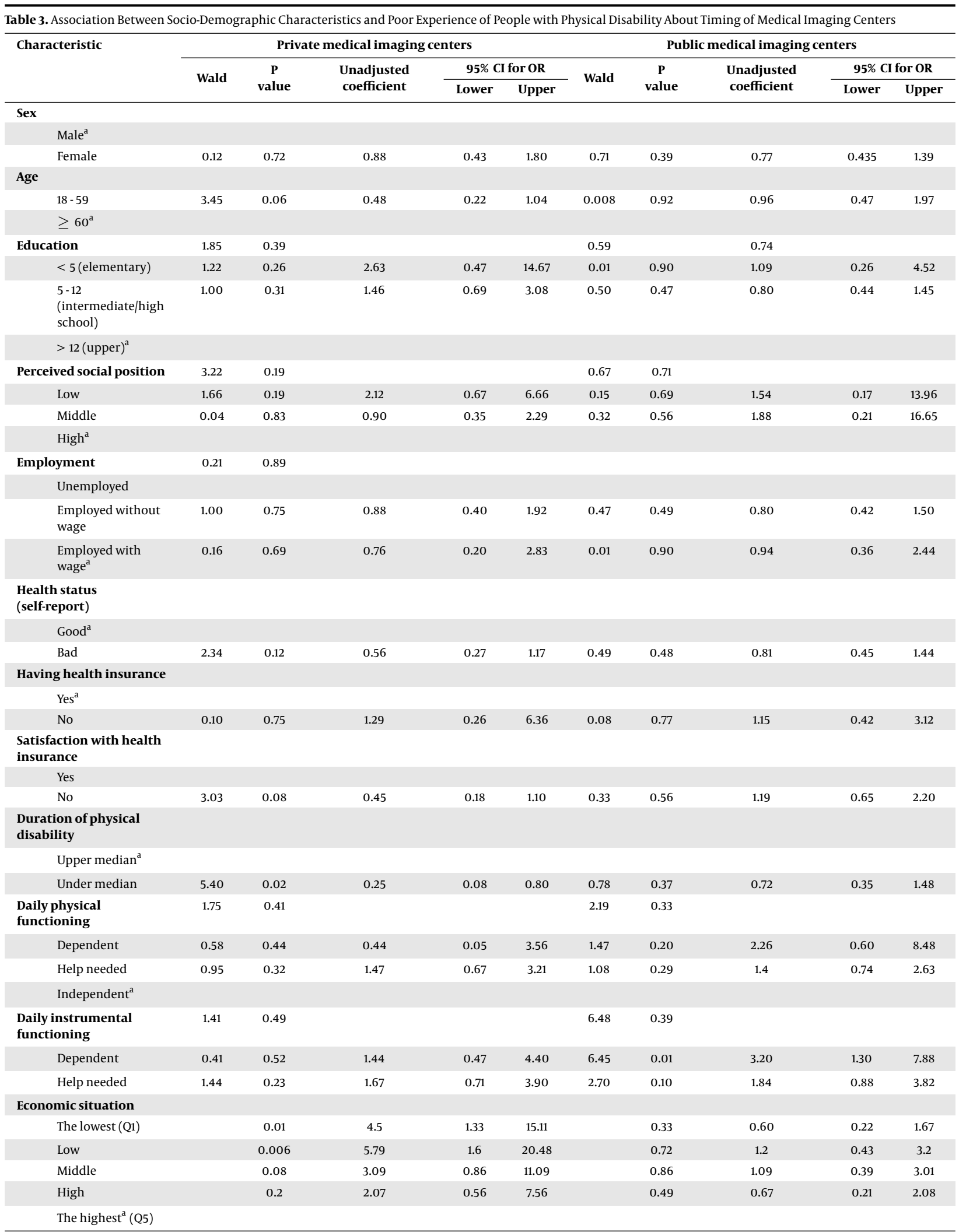

Abbreviation: $\mathrm{CI}$, confidence interval; $\mathrm{OD}$, odds ratio; $\mathrm{Q}$, quantile

${ }^{\mathrm{a}}$ Considered as reference group. 
Table 4. Multiple Regression Model of Socio-Demographic Predictors of Poor Experience of People with Physical Disability About Waiting Time of the Public Medical Imaging Centers

\begin{tabular}{|c|c|c|c|c|c|c|c|c|}
\hline \multirow{2}{*}{\multicolumn{2}{|c|}{ Variable $^{a}$}} & \multirow[t]{2}{*}{ OR } & \multirow[t]{2}{*}{ SE } & \multirow[t]{2}{*}{ Wald } & \multirow[t]{2}{*}{ DF } & \multirow[t]{2}{*}{ Pvalue } & \multicolumn{2}{|c|}{ OR 95\% CI } \\
\hline & & & & & & & Lower & Upper \\
\hline \multirow[t]{5}{*}{ IADL } & & & & 6.48 & 2 & 0.03 & & \\
\hline & Dependent & 3.2 & 0.45 & 6.45 & 1 & $0.01^{\mathrm{b}}$ & 1.3 & 7.8 \\
\hline & Help needed & 1.8 & 0.37 & 2.70 & 1 & 0.1 & 0.889 & 3.82 \\
\hline & Independent ${ }^{c}$ & & & & & & & \\
\hline & Constant & 0.2 & 0.31 & 25.2 & 1 & 0.000 & & \\
\hline
\end{tabular}

Abbreviations: CI, confidence interval; DF, degrees of freedom; IADL, instrumental activities of daily living; OR, odd ratio; SE, standard error.

${ }^{a}$ Predictors of poor experiencing about waiting time of the public medical imaging centers.

${ }^{\mathrm{b}}$ Significant $(\mathrm{P} \leq 0.05)$.

${ }^{\mathrm{c}}$ Considered as reference group.

Table 5. Multiple Regression Model of Socio-Demographic Predictors of Poor Experience of People with Physical Disability About Waiting Time of the Private Medical Imaging Centers

\begin{tabular}{|c|c|c|c|c|c|c|c|}
\hline \multirow{2}{*}{ Variable $^{a}$} & \multirow[t]{2}{*}{ OR } & \multirow[t]{2}{*}{ SE } & \multirow[t]{2}{*}{ Wald } & \multirow[t]{2}{*}{ DF } & \multirow[t]{2}{*}{ Pvalue } & \multicolumn{2}{|c|}{ OR 95\% CI } \\
\hline & & & & & & Lower & Upper \\
\hline \multicolumn{8}{|c|}{ Duration of physical disability } \\
\hline Under median & 0.28 & 0.58 & 4.5 & 1 & $0.03^{\mathrm{b}}$ & 0.09 & 0.9 \\
\hline Upper median $^{\mathrm{c}}$ & & & & & & & \\
\hline Constant & 0.29 & 0.27 & 19.8 & 1 & 0.00 & & \\
\hline
\end{tabular}

Abbreviations: CI, confidence interval; DF, degrees of freedom; OR, odd ratio; SE, standard error

${ }^{a}$ Predictors of poor experiencing about waiting time of the private medical imaging centers.

${ }^{\mathrm{b}}$ Significant $(\mathrm{P} \leq 0.05)$.

${ }^{\mathrm{c}}$ Considered as reference group.

ence in this regard. Additional research about responsiveness of medical imaging centers is recommended to be carried out in order to examine all areas and to review comprehensive information about the non-technical and nonfinancial performance of these centers from the clients' point of view. Besides, the data on sociodemographic variables were almost gathered based on participants' selfreport with probability of under-reporting.

In conclusion, it can be suggested that physical situation and capability of people with physical disability is a key factor in their experience about timeliness of the medical imaging centers. It is recommended that imaging centers ask about the physical status and duration of disability of time-seekers and so that they could consider earlier appointments for people with worse physical situation. Also, considering the better performance of private centers in timeliness than public centers based on viewpoint of people with physical disability, public centers are recommended to plan more accurately.

\section{Acknowledgments}

This article is derived from a Ph.D. thesis on responsiveness led by University of Social Welfare and Rehabilitation Sciences. We appreciate the official supports of this Univer- sity. Also, we would like to thank all the centers and participants of this study.

\section{Footnotes}

Authors' Contributions: Study concept and design: Manijeh Alavi, Ameneh Setareh Forouzan, Mohammad Reza Khodaie Ardakani, Homeira Sajjadi, Mohsen Shati and Maziar Moradi-Lakeh; acquisition of data: Manijeh Alavi; analysis and interpretation of data: Manijeh Alavi, Maziar Moradi-Lakeh, Ameneh Setareh Forouzan, Mohammad Reza Khodaie Ardakani, Homeira Sajjadi and Mohsen Shati; drafting of the manuscript: Manijeh Alavi; critical revision of the manuscript for the important intellectual content: Manijeh Alavi, Ameneh Setareh Forouzan, Mohammad Reza Khodaie Ardakani, Homeira Sajjadi, Mohsen Shati and Maziar Moradi-Lakeh; statistical analysis: Manijeh Alavi and Maziar Moradi-Lakeh; administrative, technical and material support: Manijeh Alavi, Ameneh Setareh Forouzan, Mohammad Reza Khodaie Ardakani, Homeira Sajjadi, Mohsen Shati and Maziar Moradi-Lakeh; study supervision: Maziar Moradi-Lakeh and Ameneh Setareh Forouzan.

Conflict of Interests: There is no conflict of interests. 
Financial Disclosure: The authors have no financial interests or financial conflicts within the past 5 years and for the foreseeable future in the manuscript.

Funding/Support: No financial or material supports have been received for this study.

\section{References}

1. Nuti S, Vainieri M. Managing waiting times in diagnostic medical imaging. BMJ Open. 2012;2(6). doi: 10.1136/bmjopen-2012-001255. [PubMed: 23242480]. [PubMed Central: PMC3533122].

2. Tromp N, Baltussen R. Mapping of multiple criteria for priority setting of health interventions: An aid for decision makers. BMC Health Serv Res. 2012;12:454. doi: 10.1186/1472-6963-12-454. [PubMed: 23234463]. [PubMed Central: PMC3565954].

3. Robone S, Rice N, Smith PC. Health systems' responsiveness and its characteristics: A cross-country comparative analysis. Health Serv Res. 2011;46(6pt2):2079-100. doi: 10.1111/j.1475-6773.2011.01291.x. [PubMed: 21762144]. [PubMed Central: PMC3393001].

4. Crettenden I, Poz MD, Buchan J. Right time, right place: Improving access to health service through effective retention and distribution of health workers. Hum Resour Health. 2013;11:60. doi: 10.1186/1478-449111-60. [PubMed: 24274820]. [PubMed Central: PMC4222783].

5. Winters J, Story MF, Barnekow K, Kailes JI, Premo B, Schwier E. Results of a national survey on accessibility of medical instrumentation for consumers. In: Winters J, Story MF, editors. Medical instrumentation: Accessibility and usability considerations. New York: Taylor and Fransis Group; 2007. p. 13-27.

6. Leddy KM, Kaldenberg DO, Becker BW. Timeliness in ambulatory care treatment. An examination of patient satisfaction and wait times in medical practices and outpatient test and treatment facilities.J Ambu Care Manage. 2003;26(2):138-49. doi: 10.1097/00004479-20030400000006. [PubMed: 12698928].

7. Rosenkrantz $\mathrm{AB}$, Pysarenko $\mathrm{K}$. The patient experience in radiology: Observations from over 3,500 patient feedback reports in a single institution. J Am Coll Radiol. 2016;13(11):1371-7. doi: 10.1016/j.jacr.2016.04.034. [PubMed: 27318577].

8. Xie Z, Or C. Associations between waiting times, service times, and patient satisfaction in an endocrinology outpatient department: A time study and questionnaire survey. Inquiry. 2017;54:46958017739527. doi: 10.1177/0046958017739527. [PubMed: 29161947]. [PubMed Central: PMC5798665].

9. Shirazikhah M, Mirabzadeh A, Sajadi H, Joghataei MT, Biglarian A, Mousavi T, et al. National survey of availability of physical rehabilitation services in Iran: A mixed methods study. Electron Physician. 2017;9(11):5778-86. doi: 10.19082/5778. [PubMed: 29403619]. [PubMed Central: PMC5783128]

10. Frontera WR. The World Health Organization disability action plan. Am J Phys Med Rehabil. 2014;93(9):737. doi: 10.1097/PHM.0000000000000183. [PubMed: 25137197].

11. Ramazani Ghavamabadi MH. [The protection of disable people in the international law]. Soc Welf Q. 2011;11(41):307-442. Persian.

12. Casey R. Disability and unmet health care needs in Canada: A longitudinal analysis. Disabil Health J. 2015;8(2):173-81. doi: 10.1016/j.dhjo.2014.09.010. [PubMed: 25458976].

13. Gulley SP, Rasch EK, Bethell CD, Carle AC, Druss BG, Houtrow AJ, et al. At the intersection of chronic disease, disability and health services research: A scoping literature review. Disabil Health J. 2018;11(2):192-203. doi: 10.1016/j.dhjo.2017.12.012. [PubMed: 29396271]. [PubMed Central: PMC5869152].

14. Valentine NB, de Silva A, Kawabata K, Darby C, Murray CJ, Evans DB. Health system responsiveness: concepts, domains and operationalization. In: Murray CJ AED, editor. Health systems performance assessment: Debates, methods and empiricism. Geneva: World Health Organization; 2003. p. 573-96.

15. Forouzan S, Padyab M, Rafiey H, Ghazinour M, Dejman M, San Sebastian M. Measuring the mental health-care system responsiveness: Results of an outpatient survey in Tehran. Front Public Health. 2015;3:285. doi: 10.3389/fpubh.2015.00285. [PubMed: 26858944]. [PubMed Central: PMC4728407].

16. Mitra S. A data revolution for disability-inclusive development. Lancet Glob Health. 2013;1(4):e178-9. doi: 10.1016/S2214-109X(13)700160. [PubMed: 25104340].

17. DiGiacinto D, Gildon B, Keenan LA, Patton M. Review of patient satisfaction research to improve patient surveys in medical imaging departments. J Diagn Med Sonogr. 2016;32(4):203-6. doi: $10.1177 / 8756479316650887$

18. Malhotra C, Do YK. Socio-economic disparities in health system responsiveness in India. Health Policy Plan. 2013;28(2):197-205. doi: 10.1093/heapol/czs051. [PubMed: 22709921]. [PubMed Central: PMC3584994].

19. Bramesfeld A, Wedegartner F, Elgeti H, Bisson S. How does mental health care perform in respect to service users' expectations? Evaluating inpatient and outpatient care in Germany with the WHO responsiveness concept. BMCHealth Serv Res. 2007;7:99. doi:10.1186/14726963-7-99. [PubMed: 17605786]. [PubMed Central: PMC1931438].

20. Kasalova H, Farmer RG, Roithova Z, Marx D. Development of patient satisfaction surveys in the Czech Republic: A new approach to an old theme. Int J Qual Health Care. 1994;6(4):383-8. doi: 10.1093/intqhc/6.4.383. [PubMed: 7719674].

21. Awoke MA, Negin J, Moller J, Farell P, Yawson AE, Biritwum RB, et al. Predictors of public and private healthcare utilization and associated health system responsiveness among older adults in Ghana. Glob Health Action. 2017;10(1):1301723. doi: 10.1080/16549716.2017.1301723. [PubMed: 28578615]. [PubMed Central: PMC5496095].

22. Mosallam RA, Aly MM, Moharram AM. Responsiveness of the health insurance and private systems in Alexandria, Egypt. I Egypt Public Health Assoc. 2013;88(1):46-51. doi: 10.1097/01.EPX.0000427042.54093.c4. [PubMed: 23528532].

23. De Silva A, Valentine N. A framework for measuring responsiveness. Geneva: World Health Organization; 2000.

24. Valentine N, Verdes-Tennant E, Bonsel G. Health systems' responsiveness and reporting behaviour: Multilevel analysis of the influence of individual-level factors in 64 countries. Soc Sci Med. 2015;138:152-60. doi: 10.1016/j.socscimed.2015.04.022. [PubMed: 26093073].

25. Ebrahimipour H, Vafaei Najjar A, Khani Jahani A, Pourtaleb A, Javadi M, Rezazadeh A, et al. Health system responsiveness: A case study of general hospitals in Iran. Int J Health Policy Manag. 2013;1(1):8590. doi: 10.15171/ijhpm.2013.13. [PubMed: 24596841]. [PubMed Central: PMC3937938]

26. Ghoseiri K, Bahramian H. User satisfaction with orthotic and prosthetic devices and services of a single clinic. Disabil Rehabil. 2012;34(15):1328-32. doi: 10.3109/09638288.2011.641663. [PubMed: 22200105].

27. Jorjoran Shushtari Z, Noroozi A, Mirzazadeh A, Ahounbar E, Hajbi A, Najafi $M$, et al. Comparing characteristics of earlyonset injection drug users to those with late-onset injection in Kermanshah, Iran. Subst Use Misuse. 2017;52(6):754-9. doi: 10.1080/10826084.2016.1263666. [PubMed: 28157414]. 